\title{
La estructura de las interrelaciones productivas de la economía del estado de Yucatán. Un enfoque de insumo-producto
}

\author{
Lilian Albornoz Mendoza* \\ Rodolfo Canto Sáenz* \\ Javier Becerril García*
}

Resumen: ${ }^{1}$ para evaluar los efectos de inversión pública y privada y los resultados de programas productivos y sociales de política pública, es imprescindible diseñar instrumentos de análisis económico robustos y sistemáticos. La matriz de insumo producto para la economía de Yucatán, base 2003, es la herramienta por excelencia, que contribuye a dilucidar la vinculación de los sectores de la economía, las actividades con potencial de arrastre y empuje, entender los efectos multiplicadores de alto impacto y es el idóneo para proponer objetivamente algunas líneas de acción, para incentivar un crecimiento económico equitativo y sostenido. El artículo cumple con dos objetivos: mostrar tanto el ejercicio académico de elaboración de la matriz de

\footnotetext{
* Facultad de Economía, Universidad Autónoma de Yucatán (UADY). Calle $67 \mathrm{~s} / \mathrm{n}$ por Circuito Colonias Oriente, colonia Miraflores, C. P. 97179, Mérida, Yucatán, México. Teléfono (999) 983 0362. Correos electrónicos: lilian.albornoz@uady.mx / rodolfo.canto@uady.mx / javier.becerril@uady.mx

${ }^{1}$ Los autores agradecen a la Dirección de Investigación y Desarrollo del Instituto Nacional de Estadística y Geografía (INEGI) por las facilidades otorgadas en el acceso a la base de datos de la matriz de insumo producto nacional a nivel rama. En la elaboración de esta investigación participaron Ariana Couoh Osorio, Hansell Sabido Ocampo, Adriana Valencia Medina y Amílcar Castillo Puc, quienes asistieron a los autores en la elaboración de bases de datos y cuadros y en la estimación de indicadores. El proyecto fue financiado por el Programa de Impulso y Orientación a la Investigación 2009 de la UADY.
} 
insumo producto, como la evidencia empírica de la economía de Yucatán, con la finalidad de asignar los recursos y programas de política pública a sus sectores clave.

Palabras clave: matriz de insumo producto (MIP), multiplicadores, encadenamientos, sectores clave, estrategias de promoción económica.

Abstract: to assess the effects of public and private investment and the results of social and productive public policy programs, it is essential to design robust and systematic instruments for economic analysis. The input-output matrix for the economy of Yucatan, base 2003, is the ideal instrument for clarifying the link between economic sectors and activities with a potential to drag and drive, as well as for understanding the effects of high-impact multipliers and proposing objective lines of action to encourage equitable and sustained economic growth. The article serves two purposes: to describe the academic exercise of developing the input/output matrix, and to present empirical data on the Yucatan economy, in order to inform the allocation of resources and development of public policy programs for key sectors of the economy.

Key words: input-output matrix, multipliers, chains, key sectors, economic promotion strategies.

\section{Introducción}

La contribución del comercio y los servicios es significativa para la economía yucateca, ya que en conjunto representaron 68 por ciento del producto interno bruto estatal (PIBE) en 2003. A partir de las últimas décadas del siglo xx, este tipo de actividades han ido ganando terreno, al ceder la industria manufacturera parte de su peso en la economía a partir del cierre de la industria de fibras duras CORDEMEX, 
basada en la explotación del monocultivo y manufactura del henequén (Agave fourcroydes), que representaba una parte importante del PIBE a mediados de siglo (Canto 2001). En la actualidad subsiste una industria de alimentos y bebidas con una tecnología tradicional, y en la década de 1990, con sus ciclos de expansión y contracción en determinados años, floreció la industria maquiladora con predominio del ramo textil, cuyos procesos de producción fordistas y división de trabajo taylorista han brindado muy poco o nulo aporte tecnológico a la planta industrial local (Albornoz 2000).

La existencia de enclaves de producción (industria maquiladora), de sectores tradicionales con baja productividad, de actividades terciarias que generan poca riqueza, entre otras cosas, dificulta el tránsito de la economía estatal a una senda de crecimiento equilibrado y sostenido en su PIBE y, por lo tanto, en la generación de riqueza. La población ocupada de la entidad recibe los sueldos y salarios más bajos de México; según las estadísticas de percepciones del estado, la proporción que gana hasta dos salarios mínimos asciende a 68 por ciento. En las comunidades rurales yucatecas menores de 2500 habitantes este valor es más significativo: 89 por ciento del total de la población ocupada (INEGI 2000).

En las últimas décadas, Yucatán ha perdido primacía económica en la península debido al bajo poder adquisitivo de su mercado interno y la poca competitividad de su aparato productivo, mientras Quintana Roo ha emergido con una economía pujante debido a las inversiones en infraestructura hotelera y al efecto multiplicador de la entrada de miles de millones de divisas.

El resultado de las inversiones en infraestructura comercial y servicios en Yucatán en la primera década del siglo xxI es positivo, sin embargo, no se conocen sus alcances y se presupone que su efecto multiplicador sobre la actividad económica local será muy reducido. Por otra parte, desde hace varios decenios, los gobiernos federales y recientemente los estatales han tratado de influir, a través del fomento de inversiones de todo tipo: maquiladoras, empresas agrícolas, de muebles y software, entre otras, con resultados magros hasta el momento. Aun cuando la economía yucateca experimentó tasas de crecimiento elevadas en los años noventa, sigue rezagada en 
la región peninsular y en el contexto nacional (Organización para la Cooperación y el Desarrollo Económico, OCDE 2008).

Para entender el funcionamiento de la economía estatal y determinar su potencial de crecimiento con base en sus recursos (humanos, físicos y naturales), es indispensable realizar un diagnóstico de su estructura, para identificar cuellos de botella en ciertos sectores o su grado de encadenamiento, arrastre o empuje sobre las actividades locales, que probablemente tengan poca o nula vinculación con los demás sectores, por lo cual su incidencia en el crecimiento y generación de riqueza es reducida o muy limitada. La tarea, en su caso, será identificar aquéllas con fuerte potencial de arrastre y empuje, que debido a su poco movimiento hasta ahora no ha permitido generar esos efectos multiplicadores de alto impacto. Además, este trabajo pretende cubrir el vacío en la literatura respecto a la escasez de evidencia empírica que aborda el análisis de la estructura y caracterización de la economía yucateca desde un enfoque cuantitativo.

Para cumplir con los fines expuestos, el objetivo aquí es elaborar una matriz de insumo producto del estado de Yucatán (MIPE) para 2003, que servirá de base para diagnosticar su estructura económica, así como para identificar los sectores con fuerte arrastre y empuje en la producción local, y para proponer algunas líneas de acción para incentivar un crecimiento sostenido y equilibrado.

Después de la introducción, en la segunda sección se presenta el método de regionalización de la MIPE, el marco metodológico de los efectos multiplicadores y la identificación de sectores clave; en la tercera, el diagnóstico de la estructura económica; la cuarta contiene el análisis estructural de la economía yucateca; la siguiente es una reflexión acerca de las estrategias de crecimiento viables que se sugiere instrumentar, para iniciar la marcha sostenida y creciente de la economía; por último, en las conclusiones se resumen los principales hallazgos del estudio.

Método de regionalización de la MIP nacional, multiplicadores y sectores clave

La mip es un cuadro estadístico de doble entrada, que describe el flujo de bienes y servicios entre todos los sectores económicos de una 
economía en un periodo, por lo general un año (Leontief 1986). El cuadro está compuesto por el conjunto de dichos sectores, cada uno representado en una fila y una columna, que indican su doble papel: en la columna, como consumidores y demandantes de insumos intermedios y factores productivos, y en la fila, como agentes en la distribución de la producción en bienes intermedios y finales.

Por tradición, las mip se han elaborado y usado a escala nacional, como base para la preparación de estudios enfocados a determinar las necesidades de insumos intermedios e importados de las unidades productivas y la capacidad de las industrias de proveer tales requerimientos a otras (Naciones Unidas 1999). El marco analítico fue desarrollado por Wassily Leontief a finales de la década de 1930, en la elaboración de las MIP para Estados Unidos. Las matrices han sido adoptadas y desarrolladas en todo el mundo como herramientas de planeación, análisis económico, de impacto y pronóstico (Chenery y Watanabe 1958).

Los antecedentes de la MIP de Yucatán son las matrices creadas en otras regiones del país y del mundo (Miller y Blair 2009; Flegg y Webber 2000). Las primeras hechas a escala regional se remontan a los años cincuenta (Miller y Blair 2009). En México, a partir de los años noventa, estudiosos de instituciones de educación superior y centros de investigación, así como consultores privados, se han dado a la tarea de elaborar matrices para espacios subnacionales tomando como base las realizadas a escala nacional por el INEGI para diferentes años, como la de Fuentes et al. (2004), para Baja California; Dávila (2002), para Coahuila; Núñez y Cruz (2009), para Oaxaca 2003 y Chapa et al. (2009) prepararon la de la región noreste, correspondiente a 2004. La MIPE se desarrolló a partir del marco metodológico que guió la elaboración de aquéllas, y se tomó la mip nacional a nivel rama que preparó el INEGI para 2003.

Método de regionalización

El cuadro estadístico de la MIP sirve de base en la elaboración del modelo insumo producto, al plantearse un sistema de ecuaciones lineales que expresan la interdependencia intersectorial y determi- 
nan su solución general. Para un sector i, el conjunto de ecuaciones que expresa estas relaciones se resume de la siguiente forma:

$$
x_{i}=\sum_{j=1}^{n} x_{i j}+y_{i}
$$

donde el valor bruto de la producción (vBP) del sector $i\left(x_{i}\right)$ es igual a la suma de las ventas de insumos intermedios a los sectores $j\left(\sum\right.$ $\left.{ }_{j=1}^{n} x_{i j}\right)$ y la producción de demanda final $\left(y_{i}\right)$. Esta ecuación puede ser reescrita para incluir los coeficientes técnicos de producción $\left(a_{i j}\right)$, los cuales expresan las compras que el sector $j$ hace al $i$ por valor unitario de la producción del sector $j$, y representa las compras directas de insumos intermedios del sector $j$ :

$$
x_{i}=\sum_{j=1}^{n} a_{i j} x_{j}+y_{i}
$$

En notación matricial para la economía en su conjunto $x=A x+$ $y, y$ al resolver para $x$ se obtiene la producción total entregada a la demanda final $x=(I-A)^{-1} y$, donde la matriz $(I-A)^{-1}$ es la inversa de Leontief, que representa el total de la producción que cada sector debe generar para satisfacer la demanda final de la economía.

La regionalización de la MiP nacional se basó en la estimación de coeficientes de localización de Flegg y Webber (FLQ, por sus siglas en inglés) para cada sector vendedor ( $i$ ) y comprador $(j)$ de insumos intermedios, para ajustar los coeficientes técnicos nacionales a los flujos de comercio intersectorial local. El ajuste corresponde al cálculo de la proporción $\left(t_{i j}\right)$ de los coeficientes técnicos nacionales $\left(a_{i j}\right)$ que equivalen a los intercambios intraestatales, es decir, compras y ventas de insumos intermedios de origen local. El coeficiente de localización determina el valor del estimador $\left(t_{i j}\right)$, que servirá de base para el cálculo de los coeficientes regionales de comercio $\left(r_{i j}\right)$ (Flegg et al. 1995; Flegg y Webber 1997):

$$
r_{i j}=t_{i j} a_{i j}
$$

donde el coeficiente ténico nacional $\left(a_{i j}\right)$ es igual al cociente del elemento ij $\left(x_{i j}\right)$ de la submatriz de demanda intermedia de la matriz 
de transacciones intersectoriales, y el valor total de la producción del sector j o total columna del sector $j\left(x_{j}\right)$. En la ecuación $1, t_{i j}=$ $F L Q_{i j}$ si $F L Q_{i j}<1$; en caso contrario, $t_{i j}=1$ si $F L Q_{i j} \geq 1$. Los FLQ son estimados a partir de los coeficientes de industria cruzada (CIL $\left.Q_{i j}\right)$, ponderados por el tamaño relativo $\left(\lambda_{r}^{\delta}\right)$ de la región objeto de estudio:

$$
F L Q_{i j}=\left(C I L Q_{i j}\right)\left(\lambda_{r}^{\delta}\right)
$$

donde $\left(\lambda_{r}^{\delta}\right)=\left[\log _{2}\left(1+Y_{r} / Y_{n}\right)\right]^{\delta}$ es el tamaño relativo de la región el cual es una función exponencial del logaritmo base dos del cociente del producto interno bruto (РіB) de la entidad federativa $\left(Y_{r}\right)$ y el PiB de la economía nacional $\left(Y_{n}\right)$.

A mayor participación de la economía local en relación con la economía nacional, dado un valor de $\delta=0.3$, mayor es el tamaño relativo de la región y por lo tanto más el grado de autosuficiencia de las industrias locales. El ajuste de los coeficientes técnicos nacionales es nulo para $F L Q_{i j} \geq 1$.

Los FLQ sin duda permiten calcular de forma más precisa los coeficientes regionales, en comparación con otros métodos de estimación de MIP regionales por encuestas directas y los llamados híbridos, por varias razones:

- El ajuste mejora a medida que los intercambios interindustriales locales se ponderan por el tamaño relativo de la región objeto de estudio, medido con el estimador $\lambda_{r}^{\delta}$

- La participación en el empleo o producto de las industrias en la región es comparada con la nacional, medida a través del coeficiente de localización simple $L Q_{i}$, la cual se puede expresar como:

$$
L Q_{i}=e_{i} / e_{t} /\left(E_{i} / E_{t}\right)
$$

donde $L Q_{i}$ es igual al cociente del empleo (valor agregado) local en la rama $i\left(e_{i}\right)$ y el empleo (valor agregado) local total $\left(e_{t}\right)$, en relación con el cociente del empleo (valor agregado) nacional en la rama $i\left(E_{i}\right)$ y el empleo (valor agregado) nacional total $\left(E_{t}\right)$. 
- La precisión es mayor debido a que compara el tamaño relativo de la industria vendedora $\left(L Q_{i}\right)$ y compradora $\left(L Q_{j}\right)$, medido por el coeficiente de localización de industria cruzada $\left(C I L Q_{i j}\right)$, es decir:

$$
C I L Q_{i j}=L Q_{i} / L Q_{j} \text { para } i \neq j
$$

Cuando la industria se vende a sí misma, esto es, cuando la vendedora es igual a la compradora, el FLQ deberá estimarse con el valor del coeficiente de localización simple, en lugar del valor unitario que correspondería al coeficiente de industria cruzada.

En la literatura sobre MIP y regionalización de matrices, los métodos directos, basados en la aplicación de encuestas a establecimientos y empresas representativas de la estructura económica local, son considerados como los que generan los mejores estimadores de los coeficientes regionales de comercio; sin embargo, los altos costos financieros y temporales hacen poco factible su aplicación, tanto a escala nacional como regional. Hasta el momento, Armenta (2007) elaboró la única matriz regional estimada por el método directo en México para la economía de Tabasco, para 2003.

Por otra parte, los métodos híbridos o de encuesta parcial, que permiten combinar los de regionalización y la inserción de información primaria en la MIP regional, plantean el problema de determinar empíricamente los sectores más importantes de la economía a los cuales se insertará la información "superior" (Miller y Blair 2009). En la literatura abundan los trabajos que emplean el método RAS o una de sus variantes y la inclusión de información basada en encuestas directas (Gilchrist y Louis 2004; Junius y Oosterhaven 2003; Eurostat 2002).

Por todo lo anterior, se puede afirmar que el método de estimación indirecto de la MIP para la economía de Yucatán, elegido en este trabajo, es una buena aproximación a los coeficientes de insumo producto estimados por métodos o encuestas directos, tal y como lo demuestra Tohmo en un estudio realizado para la región Keski-Pohjanmaa, en Finlandia (Tohmo 2004; Flegg y Tohmo 2011; Bonfiglio y Chelli 2008). La regionalización de la matriz nacional obtenida de esta forma permitirá contar con un instrumento de 
planeación, para el diseño y evaluación de políticas de desarrollo regional.

A partir de la MIPE de coeficientes regionales, estimada por el método FLQ, se obtuvieron dos tipos que miden la intensidad de la integración de las unidades productivas locales entre ellas. El coeficiente de encadenamiento directo hacia atrás $\left(w_{j}\right)$ de la rama j es una medida de los vínculos interindustriales directos, que resultan de la intensidad del uso de insumos intermedios de origen local, para llevar a cabo la producción de la industria $j$. Indica la proporción del valor de los insumos intermedios de origen local en el total del valor de la producción de una industria $j$. Es igual a la suma de los elementos de una columna $j$ de la MIPE de coeficientes de compras regionales. La expresión está dada por:

$$
w_{j}=\sum_{i=1}^{n} x_{i j} / X_{j}
$$

El valor del coeficiente de encadenamiento directo hacia atrás de cada actividad es normalizado para fines de comparación con el valor del resto de ellas. La normalización implica dividir el valor de una actividad por el del promedio de todas (Mariña 1993):

$$
w_{j}^{n}=w_{j} / \frac{1}{n} \sum_{j=1}^{n} w_{j}
$$

Las actividades con un índice de encadenamiento directo hacia atrás $\left(w_{j}^{n}\right)$ mayor a uno tienen un consumo intermedio de origen local por valor unitario de producto superior al promedio.

El coeficiente de encadenamiento directo hacia adelante $\left(w_{i}\right)$ es una medida de los vínculos interindustriales, que resultan de la intensidad de la venta directa de insumos intermedios de la industria $i$ a las actividades productivas locales. Indica la proporción del valor de las ventas de insumos intermedios en el total de las ventas de una industria $i$, o el valor de las ventas de insumos intermedios de la actividad $i$ por valor unitario de la producción de la actividad $i$. Es igual a la suma de los elementos de una determinada fila $i$ de la MIPE de coeficientes de ventas regionales. 


$$
w_{i}=\sum_{j=1}^{n} x_{i j} / X_{i}
$$

Los coeficientes también se normalizan para fines comparativos (Ibid.). Una actividad con un índice de encadenamiento directo hacia adelante $\left(w_{i}^{n}\right)$ superior a uno tiene un abasto de insumos intermedios por valor unitario de producto superior al promedio, $y$ tiene la siguiente expresión:

$$
w_{i}^{n}=w_{i} / \frac{1}{n} \sum_{i=1}^{n} w_{i}
$$

El análisis de la estructura productiva, en cuanto al destino de la producción y origen de insumos intermedios, se realiza con base en los índices de encadenamientos directos hacia atrás y hacia adelante (Fuentes et al. 2004; Mariña 1993) y en la clasificación sectorial de Chenery-Watanabe (1958), que está dada por el siguiente tipo de actividades:

- Las de producción primaria intermedia $w_{j}^{n}<1$ y $w_{j}^{n}>1$. Incluye a sectores con pocos vínculos con proveedores (baja demanda de insumos locales, por la naturaleza del bien que requiere pocos, o porque usan muchos insumos importados), y cuya producción se destina fundamentalmente a satisfacer la demanda intermedia (productores de insumos intermedios de uso difundido). Son actividades que se encuentran en los primeros eslabones de las cadenas productivas.

- Las de manufactura intermedia $w_{j}^{n}>1$ y $w_{i}^{n}>1$. Son las que tienen un elevado consumo intermedio directo de origen local, y cuya oferta se destina en gran parte a cubrir la demanda intermedia local. El alto consumo intermedio directo no es una condición suficiente para arrastrar a la economía ante su expansión. Son actividades situadas en los eslabones medios de las cadenas productivas.

- Las de manufactura final $w_{j}^{n}>1 y w_{i}^{n}<1$. Tienen muchos vínculos directos con proveedores locales (consumo intermedio elevado), y la oferta se destina en su mayoría a satisfacer los requerimien- 
tos de los consumidores finales (o intermedios de uso restringido). El alto consumo intermedio directo no es una condición suficiente para arrastrar a la economía ante sus impulsos positivos. Son productores de bienes finales, pero también de intermedios de uso restringido. Se encuentran en los últimos eslabones de las cadenas productivas a los cuales pertenecen.

- Las de producción primaria final $w_{j}^{n}<1 \quad y w_{i}^{n}<1$. Tienen baja demanda de insumos intermedios de origen local (ya sea por la naturaleza del producto o por el gran consumo de insumos importados) y alta oferta de bienes de consumo final (o intermedio de uso restringido).

La clasificación atiende a la estructura de la producción y no es indicativo de las interdependencias interindustriales indirectas, ya que sólo considera la demanda directa de insumos intermedios de una determinada actividad, y su oferta directa de insumos sobre el sistema económico local en su conjunto. Según Hirschman (1973), para estimular el crecimiento de la economía local se debería fomentar las actividades de altos vínculos con proveedores locales, como las de manufactura intermedia y final; las de producción primaria final son las menos relevantes en una estrategia de crecimiento económico.

Sin embargo, Fuentes (2009) ha señalado que estos índices presentan algunas limitaciones importantes, entre las cuales destaca la utilización de los coeficientes directos de la Mip, que sólo cuantifican los efectos directos y no los indirectos que provoca el incremento de la producción de una rama sobre el resto del sistema, los cuales pueden ser significativos para determinar los sectores con potencial de arrastre.

La limitación referida se resuelve por los índices de Rasmussen (1956), quien define unos coeficientes obtenidos a partir de la matriz inversa de Leontief, que Hirschman (1973) denomina coeficientes de encadenamientos totales hacia atrás y hacia adelante. Según Hirschman, la intensidad del consumo intermedio está determinada por la demanda directa e indirecta de insumos intermedios de cada sector. Las actividades más encadenadas hacia atrás tienen la característica de arrastrar al resto de los sectores a los cuales están 
encadenadas, a través de la demanda directa de insumos intermedios y de manera indirecta, pues los insumos directos requieren a su vez ser producidos con otros y así sucesivamente. Las actividades con altos índices de encadenamientos totales, que incluyen a los directos e indirectos hacia atrás, tienen fuertes efectos sobre los eslabones anteriores en las cadenas productivas.

El coeficiente de encadenamientos totales hacia atrás $\left(b_{j}^{n}\right)$, de la rama $j$, se obtiene de la suma por columna de los coeficientes $\left(b_{i j}\right)$ de la matriz inversa de Leontief $(I-A)^{-1}$. Para la rama $j$ está dado por:

$$
b_{j}=\sum_{i=1}^{n} b_{i j}
$$

El coeficiente por rama se divide por el coeficiente promedio de todos las ramas, para obtener el índice de encadenamiento total hacia atrás, es decir:

$$
b_{j}^{n}=\frac{\sum_{i=1}^{n} b_{i j}}{\frac{1}{n} \sum_{j=1}^{n} \sum_{i=1}^{n} b_{i j}}
$$

Por otra parte, las actividades que ofrecen insumos intermedios posibilitan la operación de las localizadas en eslabones posteriores en las cadenas productivas. Las actividades más encadenadas hacia adelante tienen la característica de empujar al resto de los sectores a los cuales están encadenadas, a través de la oferta directa e indirecta de insumos intermedios. Las actividades con altos índices de encadenamiento total hacia adelante tienen fuertes efectos de empuje sobre los eslabones posteriores en las cadenas productivas, cuya expansión sólo es posible con el crecimiento previo de la actividad abastecedora de insumos intermedios.

El coeficiente de encadenamiento total hacia adelante (Mariña 1993) se estima a partir de los coeficientes $\left(g_{i j}\right)$ de la matriz de ventas intersectoriales:

$$
g_{i j}=x_{i j} / X_{i}
$$


En forma matricial:

$$
G=\begin{array}{lll}
g_{11} & g_{12} \ldots & g_{1 n} \\
g_{21} & g_{22} \ldots & g_{2 n} \\
g_{n 1} & g_{n 2} \vdots & g_{n n}
\end{array}
$$

El coeficiente de encadenamiento total hacia adelante $\left(v_{i}\right)$ de la rama $i$ se obtiene de la suma por fila de los elementos $\left(v_{i j}\right)$, de la matriz inversa de ventas intersectoriales $(I-G)^{-1}$

$$
v_{i}=\sum_{j=1}^{n} v_{i j}
$$

El coeficiente por rama se divide por el coeficiente del promedio de todos los sectores, para obtener el índice de encadenamiento total hacia adelante $\left(v_{i}^{n}\right)$.

$$
v_{i}^{n}=\frac{\sum_{j=1}^{n} v_{i j}}{\frac{1}{n} \sum_{j=1}^{n} \sum_{i=1}^{n} v_{i j}}
$$

En términos de Hirschman, un sector clave es el que tiene un alto encadenamiento total tanto hacia adelante como hacia atrás. Dado que $b_{j}$ y $v_{i}$ ya se han definido como encadenamientos totales hacia atrás y hacia delante, cualquier industria con $b_{j}$ y $v_{i}$ mayores que la unidad puede considerarse como sectores clave.

La clasificación sectorial con base en los índices de encadenamientos totales hacia atrás y hacia adelante distingue cuatro tipos de categorías: sectores base, sectores clave, de fuerte arrastre e independientes, que muestran las interdependencias interindustriales y la compleja red de relaciones que se da entre las actividades (Ibid.).

Multiplicadores de empleo e ingreso

Una política de planeación regional con objetivos diferenciados se deberá elaborar con base en herramientas cuantitativas, que permitan identificar las potencialidades de la economía local y las ramas 
que inducen los mayores efectos, según el fin que se persigue. En la planeación del desarrollo económico local, la política de fomento al empleo de fuentes formales y de alto contenido tecnológico juega un papel destacado como primer paso, para iniciar un proceso de crecimiento sostenido y equilibrado, por lo que es necesario identificar los sectores que inducen la creación sostenida de empleos y generación de ingresos elevados. Es posible la identificación de las ramas con alto poder de creación de empleo formal y altamente remunerativas a partir de la estimación de multiplicadores de empleo e ingreso, con base en la información presentada en la MIPE.

Fomentar el empleo estimularía la actividad, con los mayores efectos multiplicadores sobre él (Han 1995). El aumento en la demanda final de un sector incentiva su producción, que al principio crece en la misma cantidad. La producción adicional requiere insumos intermedios, que a su vez deben ser fabricados por otras industrias; los de la primera ronda se suman a los de la segunda y así indefinidamente, hasta formar una cadena de insumos que permite la producción adicional, para cubrir el aumento en la demanda final. Dicho mecanismo multiplica los empleos, de tal forma que el crecimiento inicial en éstos se ve reforzado por su incremento indirecto en la producción de la cadena de insumos intermedios. El efecto multiplicador en el empleo local es la suma del directo e indirecto. Las actividades intensivas en mano de obra por unidad de producción no provocan necesariamente efectos multiplicadores elevados en el empleo cuando el efecto indirecto es reducido, aunque puede ser importante en una actividad a la hora de determinar la política para fomentarlo.

Los multiplicadores del empleo miden los requerimientos de éste (número de trabajadores), de un millón de incremento en el valor de la demanda final, resultan de las demandas de insumos intermedios directos (primera ronda) e indirectos (de segunda) en la producción, para satisfacer el aumento en la demanda final (Miller y Blair 2009; Han 1995). La expresión en forma matricial está dada por:

$$
m=l(I-A)^{-1}
$$


El vector de multiplicadores de empleo $(m)$ es igual al producto matricial del vector de empleo $(l)$ y la matriz inversa de Leontief $(I-A)^{-1}$, que en adelante se representará como la matriz $B$. Un elemento del vector de empleo está dado por el cociente del empleo en la rama $i\left(e_{i}\right)$ y el valor bruto de la producción en la rama $i\left(x_{i}\right)$.

$$
l_{i}=e_{i} / X_{i}
$$

Por otra parte, los multiplicadores de ingreso miden el efecto directo e indirecto en el ingreso de los factores productivos (trabajadores, empresarios, dueños de propiedades) de un millón de incremento en la demanda final. Los efectos indirectos de la cadena de insumos pueden ser importantes y mayores a los directos. En esta investigación se obtienen los multiplicadores de ingreso tipo I, que son los de ingreso (total columna) del sector j, divididos por el coeficiente directo de valor agregado por unidad de producto de su respectivo sector (Miller y Blair 2009). En notación matricial:

$$
h=z(I-A)^{-1}
$$

donde el vector del multiplicador del ingreso $(h)$ es igual al producto matricial del vector de valor agregado por unidad de producto $(z)$ y la matriz inversa de Leontief $(I-A)^{-1}$. Un elemento del vector de valor agregado por unidad de producto $\left(z_{j}\right)$ es igual al valor agregado bruto del sector $j\left(z_{j}\right)$ y el valor bruto de la producción del mismo sector $j\left(x_{j}\right)$, es decir:

$$
z_{j}=z_{j} / X_{j}
$$

El multiplicador de ingreso tipo I de la rama $j\left(h_{i j}^{I}\right)$, el cual indica el número de veces que el ingreso inicial se reproduce en el sistema, está dado por la expresión:

$$
h_{i j}^{I}=\frac{h_{i j}}{z_{j}}
$$


donde el numerador $\left(h_{i j}\right)$ del cociente es un elemento del vector del multiplicador de empleo. Como ya se mencionó, los multiplicadores de ingreso tipo i muestran cuántas veces se reproduce en el sistema económico el efecto inicial en el ingreso, debido al aumento de un millón de pesos en la demanda final del sector j, y está dado por el coeficiente directo de valor agregado por unidad de producto $z_{j}$ (Ibid.). Los multiplicadores se normalizaron para facilitar la comparación entre ramas; las de índices superiores a uno tienen un multiplicador mayor al promedio de las restantes; las de índices menores a uno tienen un multiplicador menor al promedio de las restantes. $^{2}$

\section{Matriz de insumo producto de la economía de Yucatán}

La MIPE se elaboró a nivel rama, según el Sistema de Clasificación Industrial de América del Norte (SCIAN) ${ }^{3}$ (INEGI 2002). La MIPE de la economía de Yucatán es la primera matriz que se elabora en México a este nivel de desagregación, por lo que constituye el primer esfuerzo por representar de manera más detallada las relaciones interindustriales de una economía local. Se distinguen 216 actividades económicas a nivel rama scian. La elaboración de la base de datos se facilitó debido a la coincidencia en el clasificador de las actividades del Censo económico 2004 y la adoptada en la presentación de la MIP nacional de 2003. ${ }^{4}$

${ }^{2}$ El ranking de sectores cuando se toman como referencia los efectos multiplicadores de empleo-producción e ingreso-producción, en el modelo de insumo producto abierto, es el mismo que cuando se consideran los efectos del consumo de los hogares, en el modelo de insumo producto cerrado al consumo (Ten Raa 2005).

${ }^{3}$ El sCiAn considera cinco niveles de agregación de las actividades económicas: sector, subsector, rama, subrama y clase de actividad. El sector es el más general y está integrado por 20 categorías, representado por un código de dos dígitos; el subsector está formado por 95, con un código de tres dígitos; la rama por 309, y se representa por códigos de cuatro dígitos; la subrama por 631, y códigos de cinco dígitos y la clase de actividad, el más desagregado de la clasificación, por 1051 categorías, con códigos de seis dígitos.

${ }^{4}$ El INEGI adoptó la clasificación de actividades propuesta por sCiAN en el diseño y elaboración del Censo económico 2004, la misma que sirvió de base para la presentación de la MIP nacional de 2003; primera matriz construida con esta clasificación, pues las anteriores habían empleado la del Sistema de Cuentas Nacionales (Fuentes et al. 2004; Dávila 2002). La Clasificación Mexicana de Actividades y Productos era la que se usaba para la codificación de las 
El valor bruto de la producción es la variable empleada en la estimación de los coeficientes de localización. Los datos del vBP para la pesca, acuacultura, manufactura, comercio y servicios se obtuvieron del Censo económico 2004 del INEGI; los correspondientes al sector agrícola y pecuario se consiguieron en la base de datos del Sistema de Información Agroalimentaria y Pesquera (SIAP), de la Secretaría de Agricultura, Ganadería, Desarrollo Rural, Pesca y Alimentación (SAGARPA) y del Anuario estadístico del estado de Yucatán 2004, para las actividades forestales y de gobierno.

No fue posible obtener los coeficientes de localización a partir de los datos de empleo y valor agregado bruto (VAB); los datos de empleo disponibles a nivel rama son incompatibles entre las fuentes (Encuesta nacional de ocupación y empleo, ENOE, y censo económico), debido a diferencias conceptuales de las categorías de empleo y ocupación, de discrepancias en las metodologías usadas en el cálculo y de que cada proyecto no reporta las estadísticas de cada actividad, por lo que se decidió prescindir de esta información para estimarlos.

Además, los datos del valor agregado a nivel rama, para algunas de las actividades manufactureras y de servicio, publicados por el Censo económico 2004, contienen valores negativos, ${ }^{5}$ que al emplearlos en la estimación de los coeficientes de localización arrojaban resultados sin sentido económico. De ahí que se optara por usar la base de datos estatal y nacional del vBP a partir de la información contenida en el Censo económico 2004, anuarios estatales y SIAP (2010). Se realizaron pruebas para comparar los valores de los coeficientes de localización simple, estimados con base en el VAB y VAP, para las actividades en las cuales se disponían de ambos datos (en específico, las manufactureras). Los resultados arrojaron que las estimaciones con datos del vBP son más conservadores en relación con los obtenidos con los del vaB, ya que los basados en el vBP la

actividades en los censos económicos, la última publicada con esta base corresponde al censo de 1998.

${ }^{5}$ El vaB es la diferencia entre el vBP y el valor del consumo intermedio. Por lo tanto, los datos censales arrojan un comercialización de la producción son menores a los gastos en consumo intermedio; esto es así para las unidades auxiliares, las unidades económicas sin fines de lucro, aquéllas que dependen fuertemente de subsidios y donaciones y unidades en quiebra financiera (INEGI 2004). 
mayoría de las veces fueron menores a los calculados con el vaB, y la diferencia promedio en relación con el vaB fue de -0.15 por ciento.

En la estimación de la matriz de transacciones intersectoriales de la economía de Yucatán se tomaron los datos del PIBE a precios básicos, como indicador del VAB a precios básicos. La serie del PIBE disponible tiene desagregación a 20 sectores, el manufacturero presenta a su vez otra desagregación en nueve grandes industrias. Se eliminaron las actividades inexistentes a nivel rama en la economía local, y la participación de las ramas restantes en el PIB del sector respectivo se estimó con base en la importancia relativa en el empleo formal del sector. Los componentes de la demanda final se calcularon de la siguiente forma (Dávila 2002; Fuentes et al. 2004): a) consumo de los hogares. El consumo per cápita nacional fue la base para la estimación del consumo final de bienes y servicios, sólo que ajustado por el índice de ingreso medio; ${ }^{6}$ b) consumo del gobierno. El gasto gubernamental per cápita nacional sirvió para calcular el valor del gasto a nivel rama, el total fue ajustado al valor del agregado estatal; c) formación bruta de capital fijo. El vBP estatal por rama y los promedios nacionales de participación del capital fijo permitieron estimar los valores a escala estatal y d) exportaciones. La diferencia entre el vBP y los componentes de las demanda final (consumo hogares, gobierno y formación bruta de capital) e intermedia.

En la estimación de las importaciones interestatales se obtuvieron, como primer paso, los coeficientes técnicos de dicha variable como la diferencia entre el de los usos de la economía de origen nacional para cada rama, tomados de la mip nacional y el de los usos de la economía local también para cada rama, conseguido de la regionalización de la MIP. Los coeficientes de las importaciones interestatales se multiplicaron por el vBP para cada rama correspondiente. Las importaciones internacionales, el VAB y los impuestos se estimaron con base en los coeficientes de participación nacional.

La matriz de la economía estatal (véase figura 1) se elaboró con base en un modelo de demanda abierto al consumo de los hogares, ya que éste se determina en forma exógena al sistema de transaccio-

\footnotetext{
${ }^{6}$ El índice de ingreso medio se obtuvo como el cociente de la proporción del PIBE en el PIB nacional y la proporción de la población en Yucatán en la de México.
} 
nes intersectoriales. A continuación se realiza una caracterización de la economía local, con base en la información de la MIP.

Producto interno bruto y productividad laboral

La economía yucateca está orientada al secor servicios (claves 4893), ya que genera la mitad más uno del PIBE (51 por ciento). La participación sectorial en el PIBE para 2003 se presenta agregada en 19 sectores (INEGI 2002) en la figura 2; el de comercio (mayoreo y menudeo) tiene la mayor, con 17 por ciento del PIBE. Le sigue la industria manufacturera (16) y los servicios inmobiliarios y de alquiler de bienes muebles e intangibles (13). El sector comercial es más importante en la generación de riqueza (17 por ciento) y empleo formal (25), en comparación con la industria manufacturera (16 y 21 por ciento, respectivamente) (INEGI s/f; 2005a). La alta participación individual de los servicios inmobiliarios y de alquiler de bienes muebles e intangibles indica su grado de desarrollo; en los últimos años la economía local se ha caracterizado por la ofertaamplia de bienes inmuebles y muebles para renta. El empleo en este último sector representa 1 por ciento del volumen total.

Con base en los porcentajes de participación de cada sector en el PIBE y empleo formal, ${ }^{7}$ se obtuvieron índices de productividad media para cada uno; el mayor fue para los servicios inmobiliarios y de alquiler, con 13.53, muy superior al de información en medios masivos, que ocupó el segundo sitio, con 4.33. Le siguen los servicios financieros y de seguros (2.69); transportes, correos y almacenamiento (2.49); dirección de corporativos y empresas (2.30); servicios educativos (2.20); servicios de salud y asistencia social (2.14); minería (1.95); electricidad y agua (1.92); construcción (1.83) y servicios profesionales, científicos y técnicos (1.35), que en conjunto emplean a 18 por ciento de los trabajadores formales.

${ }^{7}$ El dato de empleo formal incluye otros datos estimados, como el aproximado de los empleados domésticos, con base en la ENOE y el aproximado de actividades agropecuarias y forestales, con base en INEGI (2007). El empleo doméstico corresponde a la rama hogares, con trabajadores domésticos; el de actividades agropecuarias y forestales a las ramas agricultura, explotación de bovinos, de porcinos, avícola, de ovinos y caprinos, de otros animales y aprovechamiento forestal. Los datos de empleo para todas las demás ramas se obtuvieron del INEGI (2004). 
Los sectores con las peores productividades constituyen 82 por ciento del empleo formal total; las actividades que tienen las más bajas son las representadas por la agricultura, ganadería, aprovechamiento forestal, pesca y caza, con 66 por ciento menores a la productividad media y otros servicios, con 70 por ciento menores a la media. Otras con índices muy bajos son servicios de apoyo a negocios (0.54); de alojamiento temporal y restaurantes (0.55); de esparcimiento (0.73); comercio (0.70); actividades del gobierno $(0.75)$ e industria manufacturera $(0.77)$.

\section{Figura 1}

Matriz de insumo producto de la economía de Yucatán 2003, millones de pesos

\begin{tabular}{|c|c|c|c|c|c|c|c|c|c|c|c|c|c|c|}
\hline & 11 & 21 & 22 & 23 & $31-33$ & 43 y 46 & $48-49$ & 51 & 52 & 53 & 54 & 55 & 56 & 61 \\
\hline 11 & 98 & 0 & 0 & 4 & 1809 & 0 & 0 & 0 & 0 & 0 & 0 & 0 & 0 & 0 \\
\hline 21 & 1 & 19 & 0 & 73 & 191 & 0 & 0 & 0 & 0 & 3 & 0 & 0 & 0 & 0 \\
\hline 22 & 48 & 9 & 561 & 16 & 346 & 147 & 26 & 28 & 9 & 103 & 15 & 1 & 6 & 24 \\
\hline 23 & 8 & 2 & 4 & 468 & 32 & 4 & 8 & 1 & 4 & 37 & 0 & 3 & 2 & 10 \\
\hline $31-33$ & 243 & 11 & 8 & 541 & 2082 & 91 & 43 & 104 & 6 & 48 & 31 & 2 & 28 & 11 \\
\hline $43 y 46$ & 126 & 12 & 64 & 248 & 1401 & 173 & 181 & 71 & 12 & 50 & 52 & 2 & 26 & 14 \\
\hline $48-49$ & 37 & 6 & 28 & 77 & 503 & 70 & 110 & 29 & 31 & 23 & 29 & 6 & 13 & 11 \\
\hline 51 & 15 & 1 & 2 & 4 & 79 & 79 & 24 & 15 & 20 & 13 & 24 & 2 & 10 & 43 \\
\hline 52 & 8 & 1 & 1 & 2 & 51 & 24 & 9 & 32 & 124 & 2 & 1 & 1 & 1 & 0 \\
\hline 53 & 2 & 15 & 7 & 24 & 158 & 121 & 68 & 44 & 65 & 45 & 40 & 3 & 13 & 24 \\
\hline 54 & 18 & 2 & 2 & 42 & 291 & 245 & 63 & 64 & 100 & 20 & 45 & 13 & 27 & 15 \\
\hline 55 & 0 & 0 & 0 & 0 & 31 & 1 & 1 & 15 & 0 & 0 & 0 & 1 & 0 & 0 \\
\hline 56 & 0 & 0 & 3 & 17 & 168 & 10 & 27 & 18 & 102 & 5 & 13 & 1 & 7 & 17 \\
\hline 61 & 0 & 0 & 0 & 0 & 0 & 0 & 1 & 0 & 5 & 0 & 2 & 0 & 0 & 2 \\
\hline 62 & 0 & 0 & 0 & 0 & 0 & 0 & 0 & 0 & 0 & 0 & 0 & 0 & 0 & 0 \\
\hline 71 & 0 & 0 & 0 & 0 & 0 & 0 & 0 & 1 & 0 & 0 & 0 & 0 & 0 & 0 \\
\hline 72 & 0 & 0 & 2 & 10 & 49 & 0 & 18 & 5 & 11 & 2 & 8 & 5 & 5 & 5 \\
\hline 81 & 5 & 3 & 14 & 10 & 106 & 29 & 78 & 25 & 15 & 15 & 6 & 2 & 3 & 6 \\
\hline 93 & 0 & 0 & 6 & 0 & 0 & 0 & 27 & 0 & 7 & 0 & 0 & 0 & 0 & 0 \\
\hline UEIL & 608 & 83 & 701 & 1535 & 7298 & 993 & 685 & 452 & 511 & 366 & 267 & 42 & 141 & 182 \\
\hline & & & & & & & & & & & & & & \\
\hline$M$ & 4419 & 209 & 2148 & 6907 & 18319 & 4727 & 3260 & 1485 & 587 & 1125 & 702 & 129 & 242 & 488 \\
\hline MNaC & 3960 & 163 & 1699 & 5731 & 11602 & 3810 & 2485 & 1166 & 460 & 1019 & 535 & 100 & 174 & 433 \\
\hline Mint & 459 & 45 & 449 & 1176 & 6717 & 917 & 775 & 319 & 127 & 106 & 168 & 29 & 68 & 55 \\
\hline & & & & & & & & & & & & & & \\
\hline ISPNS & 30 & 6 & 46 & 57 & 105 & 8 & 183 & 14 & 0 & 3 & 5 & 0 & 2 & 1 \\
\hline VAB & 4202 & 643 & 1822 & 8140 & 15636 & 16624 & 6624 & 3152 & 431 & 12988 & 2417 & 197 & 1290 & 5803 \\
\hline Rem & 1064 & 146 & 709 & 3283 & 4522 & 4031 & 2249 & 826 & 439 & 185 & 608 & 112 & 777 & 4425 \\
\hline INSP & 5 & 7 & 11 & 30 & 99 & 168 & 13 & 21 & 31 & 131 & 8 & 36 & 8 & 15 \\
\hline EBO & $\begin{array}{lll}3 & 132\end{array}$ & 490 & $\begin{array}{lll}1 & 1 & 02\end{array}$ & 4827 & $\begin{array}{llll}1 & 1 & 0 & 15\end{array}$ & 12424 & 4362 & 2305 & 960 & 12672 & 1801 & 49 & 505 & 1363 \\
\hline UsosPc & 5056 & 297 & 2895 & 8500 & 25722 & 5728 & 4128 & 1952 & 1097 & 1494 & 974 & 172 & 385 & 671 \\
\hline & & & & & & & & & & & & & & \\
\hline VBP & 9258 & 940 & 4717 & 16640 & 41358 & 22352 & 10753 & 5104 & 2528 & 14482 & 3391 & 369 & 675 & 6474 \\
\hline & & & & & & & & & & & & & & \\
\hline PIBM & 4231 & 649 & 1868 & 8197 & 15742 & 16632 & 6808 & 3166 & 1431 & 12991 & 2422 & 197 & $\begin{array}{ll}1 & 292 \\
\end{array}$ & 5804 \\
\hline
\end{tabular}




\section{Continuación de figura 1}

\begin{tabular}{|c|c|c|c|c|c|c|c|c|c|c|c|}
\hline 62 & 71 & 72 & 81 & 93 & DI & $\mathrm{CP}$ & CG & FBK & $\mathrm{X}$ & $\mathrm{DF}$ & VBP \\
\hline 0 & 0 & 0 & 0 & 0 & 1911 & 2045 & 0 & 561 & 4741 & 7347 & 9258 \\
\hline 0 & 0 & 0 & 0 & 0 & 287 & 0 & 0 & 119 & 535 & 654 & 940 \\
\hline 32 & 6 & 90 & 39 & 41 & 1546 & 1089 & 0 & 0 & 2082 & 3171 & 4717 \\
\hline 4 & 0 & 7 & 1 & 7 & 601 & 703 & 0 & 15225 & 110 & 16038 & 16640 \\
\hline 39 & 11 & 56 & 73 & 16 & 3444 & 15236 & 21 & 2879 & 19778 & 37914 & 41358 \\
\hline 67 & 8 & 35 & 58 & 16 & 2615 & 8987 & 0 & 1342 & 9408 & 19737 & 22352 \\
\hline 21 & 3 & 14 & 25 & 22 & 1058 & 7037 & 0 & 246 & 2412 & 9694 & 10753 \\
\hline 9 & 3 & 18 & 28 & 5 & 394 & 2234 & 1 & 0 & 2475 & 4710 & 5104 \\
\hline 1 & 0 & 2 & 3 & 1 & 264 & 1256 & 0 & 0 & 1008 & 2264 & 2528 \\
\hline 18 & 8 & 30 & 30 & 15 & 731 & 9060 & 0 & 0 & 4690 & 13750 & 14482 \\
\hline 13 & 4 & 17 & 30 & 15 & 1027 & 1532 & 139 & 0 & 694 & 2364 & 3391 \\
\hline 0 & 0 & 0 & 0 & 0 & 49 & 0 & 0 & 0 & 319 & 319 & 369 \\
\hline 24 & 4 & 9 & 7 & 14 & 445 & 284 & 0 & 0 & 945 & 1230 & 1675 \\
\hline 1 & 0 & 0 & 0 & 7 & 20 & 1893 & 3094 & 0 & 1467 & 6454 & 6474 \\
\hline 0 & 0 & 0 & 0 & 0 & 0 & 1753 & 1866 & 0 & 1253 & 4872 & 4872 \\
\hline 0 & 0 & 0 & 0 & 0 & 1 & 472 & 49 & 0 & -45 & 476 & 477 \\
\hline 4 & 1 & 1 & 3 & 5 & 134 & 3279 & 0 & 0 & 885 & 4163 & 4297 \\
\hline 14 & 2 & 13 & 4 & 20 & 369 & 3119 & 0 & 0 & 1021 & 4140 & 4509 \\
\hline 0 & 0 & 0 & 0 & 0 & 41 & 57 & 4745 & 0 & 1131 & 5933 & 5974 \\
\hline 247 & 51 & 292 & 301 & 184 & 14937 & 60037 & 9914 & 20371 & 54910 & 145231 & 160169 \\
\hline & & & & & & & & & & & \\
\hline 927 & 90 & 874 & 847 & 1299 & 48784 & 7612 & 53 & 9976 & 3541 & 21181 & 69965 \\
\hline 741 & 79 & 819 & 581 & 1238 & 36794 & & & & & 4320 & 41114 \\
\hline 186 & 11 & 55 & 267 & 61 & 11990 & & & & & 16861 & 28851 \\
\hline 6 & 0 & 5 & 7 & 12 & 491 & 5179 & & 68 & & 5247 & 5738 \\
\hline 3693 & 336 & 3127 & 3354 & 4479 & 95956 & & & & & & \\
\hline 2115 & 92 & 884 & 1146 & 4420 & 32035 & & & & & & \\
\hline 10 & 4 & 18 & 10 & 34 & 659 & & & & & & \\
\hline 1567 & 240 & 2225 & 2198 & 25 & 63263 & & & & & & \\
\hline 1180 & 141 & 1171 & 1155 & 1495 & 64212 & 72827 & 9966 & 30415 & 58451 & 171659 & 235871 \\
\hline & & & & & & & & & & & \\
\hline 4872 & 477 & 4297 & 4509 & 5974 & \begin{tabular}{|lll}
160 & 169 \\
\end{tabular} & & & & & & \\
\hline 3698 & 336 & $\begin{array}{lll}3 & 132\end{array}$ & 3361 & 4491 & 96448 & 5179 & & 68 & & 5247 & 101694 \\
\hline
\end{tabular}

UEIL: usos de la economía interna de origen local;

M: importaciones interestatales e internacionales;

MNac: importaciones interestatales;

MInt: importaciones internacionales;

ISPNS: impuestos sobre los productos netos de subsidios;

VAB: valor agregado bruto de la economía interna;

Rem: total de remuneración de asalariados;

INSP: impuestos netos de subsidios sobre la producción;

EBO: excedente bruto de operación;

UsosPc: total usos a precios comprador;

PIB: producto interno bruto a precios de mercado;

DI: demanda intermedia;

CP: consumo privado;

CG: consumo del gobierno;

FBK: formación bruta del capital;

$\mathrm{x}$ : exportaciones interestatales e internacionales;

DF: demanda final;

vBP: valor bruto de la producción.

Fuente: elaboración propia, con base en la MIP nacional a nivel rama del INEGI $(2003 ; 2004$; 2005b y 2003-2007); SIAP-SAGARPA (2010). 


\section{Figura 2}

Participación sectorial en el PIB y empleo estatales, 2003

\begin{tabular}{|c|c|c|c|c|c|c|}
\hline Código & Sector & PIB & $\%$ & \begin{tabular}{|l|} 
Empleo \\
formal
\end{tabular} & $\%$ & $\begin{array}{c}\text { Productividad } \\
\text { media }\end{array}$ \\
\hline 11 & $\begin{array}{l}\text { Agricultura, ganadería, } \\
\text { aprovechamiento forestal, } \\
\text { pesca y caza }\end{array}$ & 4231.39 & 4.39 & 39748 & 10.05 & 0.44 \\
\hline 21 & Minería & 649.06 & 0.67 & 1368 & 0.35 & 1.95 \\
\hline 22 & Electricidad y agua & 1868.02 & 1.94 & 3990 & 1.01 & 1.92 \\
\hline 23 & Construcción & 8197.12 & 8.50 & 18329 & 4.63 & 1.83 \\
\hline $31-33$ & Industrias manufactureras & 15741.33 & 16.32 & 83865 & 21.20 & 0.77 \\
\hline 43 y 46 & Comercio & 16631.59 & 17.24 & 97276 & 24.59 & 0.70 \\
\hline $48-49$ & $\begin{array}{l}\text { Transportes, correos } \\
\text { y almacenamiento }\end{array}$ & 6807.60 & 7.06 & 11204 & 2.83 & 2.49 \\
\hline 51 & $\begin{array}{l}\text { Información en medios } \\
\text { masivos }\end{array}$ & 3166.04 & 3.28 & 3000 & 0.76 & 4.33 \\
\hline 52 & $\begin{array}{l}\text { Servicios financieros } \\
\text { y de seguros }\end{array}$ & 1430.54 & 1.48 & 2182 & 0.55 & 2.69 \\
\hline 53 & $\begin{array}{l}\text { Servicios inmobiliarios } \\
\text { y de alquiler }\end{array}$ & 12991.00 & 13.47 & 3938 & 1.00 & 13.53 \\
\hline 54 & $\begin{array}{l}\text { Servicios profesionales, } \\
\text { científicos y técnicos }\end{array}$ & 2422.16 & 2.51 & 7361 & 1.86 & 1.35 \\
\hline 55 & $\begin{array}{l}\text { Dirección de corporativos } \\
\text { y empresas }\end{array}$ & 197.30 & 0.20 & 352 & 0.09 & 2.30 \\
\hline 56 & $\begin{array}{l}\text { Servicios de apoyo a } \\
\text { negocios y otros }\end{array}$ & 1292.19 & 1.34 & 9762 & 2.47 & 0.54 \\
\hline 61 & Servicios educativos & 5803.85 & 6.02 & 10808 & 2.73 & 2.20 \\
\hline 62 & $\begin{array}{l}\text { Servicios de salud } \\
\text { y de asistencia social }\end{array}$ & 3698.48 & 3.83 & 7100 & 1.80 & 2.14 \\
\hline 71 & $\begin{array}{l}\text { Servicios de esparcimiento } \\
\text { culturales y deportivos } \\
\text { y otros }\end{array}$ & 336.01 & 0.35 & 1891 & 0.48 & 0.73 \\
\hline 72 & $\begin{array}{l}\text { Servicios alojamiento } \\
\text { temporal y preparación } \\
\text { de alimentos y bebidas }\end{array}$ & 3131.72 & 3.25 & 23531 & 5.95 & 0.55 \\
\hline 81 & $\begin{array}{l}\text { Otros servicios, excepto } \\
\text { actividades del gobierno }\end{array}$ & 3361.28 & 3.49 & 45217 & 11.43 & 0.30 \\
\hline \multirow[t]{2}{*}{93} & Actividades del gobierno & 4490.71 & 4.66 & 24601 & 6.22 & 0.75 \\
\hline & PIB a precios de mercado & 96447.39 & 100.00 & 395522 & 100.00 & \\
\hline
\end{tabular}

Fuente: elaboración propia, con base en INEGI (2003-2007; s/f; 2005b y 2007). 
Exportaciones a otros estados y países

Las exportaciones totales a otras entidades federativas y países en 2003 ascendieron a 58451 millones de pesos. El valor de las libres a bordo (free on board, FOB, por sus siglas en inglés) fue de 54919 millones de pesos y las compras de bienes de origen local de no residentes en Yucatán, de 3541 millones de pesos. Con base en los datos de la Secretaría de Fomento Económico (SEFoe s/f), el valor de las exportaciones internacionales para 2004 fue de 13114 millones de pesos y, si su evolución de un año a otro presenta una tendencia estable, se deduce que el destino de la mayor parte de ellas (76 por ciento), de 2003, es el mercado de otros estados del país.

Las principales actividades exportadoras a otras entidades federativas y países por su valor total, en el orden que se presentan en el sector secundario son: confección de prendas de vestir (4 por ciento); industria de las bebidas (4); elaboración de productos de panadería y tortillas (3); matanza, empacado y procesamiento de carne de ganado y aves (3); fabricación de cemento y productos de concreto (2). Las exportaciones del sector manufacturero (en conjunto) son las de mayor valor, 36 por ciento de ellas FoB, ya que envía a otros estados y países.

Coeficientes de localización simple

La economía yucateca tiene alta especialización en varias ramas del sector primario; destaca su participación, en relación con el promedio de la industria nacional en la explotación de porcinos y de otros animales (apicultura) y pesca. Por parte del sector secundario, la economía tiene una vocación en industrias de alimentos y textiles; en la primera resalta la preparación y envasado de pescados y mariscos, y en la segunda el acabado y recubrimiento de textiles. En cuanto a la especialización terciaria, sobresalen el transporte marítimo y servicios de capacitación para el trabajo. Las ramas mencionadas tienen coeficientes de localización simples, superiores a seis unidades. El coeficiente indica que la participación de la rama en la economía local es igual a tantas veces (el valor del coeficiente) la participación promedio nacional. En la figura 3 se presentan las ra- 
mas con coeficientes de localización superior a dos unidades, según tipo de actividad.

\section{Figura 3}

Ramas más importantes según coeficientes de localización simple

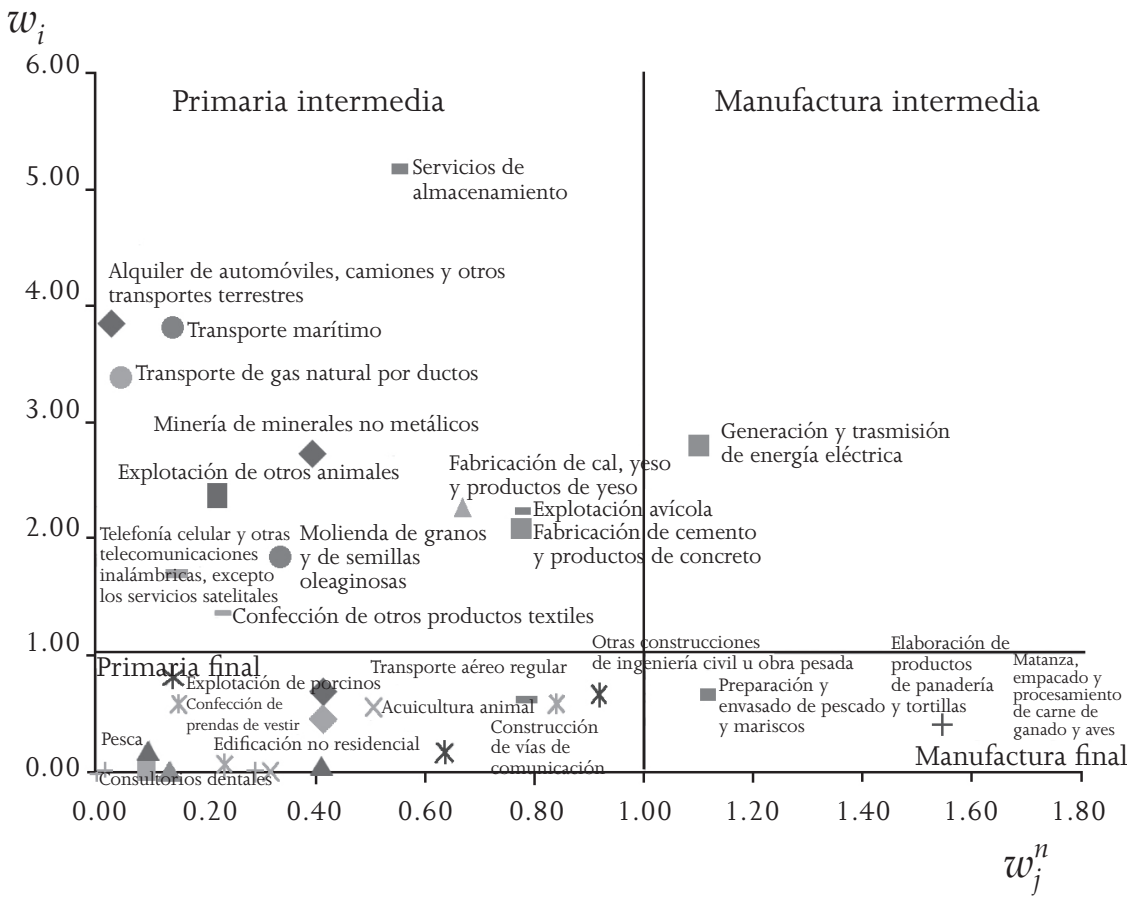

Fuente: elaboración propia, con base en INEGI (2004 y 2005b); SIAP-SAGARPA (2010).

La participación de la explotación de otros animales (apicultura) en la economía local es 11 veces mayor a la del promedio nacional. El estado es uno de los principales productores de miel de México; en 2008 ocupó el primer lugar, con 9774 toneladas (SIAP-SAGARPA 2010). La pesca y la preparación y envasado de pescados y mariscos también tienen una participación mayor a la observada a escala nacional, de más de seis veces, y están relacionadas ya que forman parte de la misma cadena de producción. El transporte marítimo también destaca, con una participación seis veces mayor al pro- 
medio nacional. El puerto de altura de Progreso es uno de los más importantes de la península en cuanto a movimiento de carga.

La explotación de porcinos también es relevante, medida por el coeficiente de localización simple (6.66). Yucatán es uno de los principales productores de ganado porcino en pie y de carne en canal, que exporta a otros estados y países. La matanza, empacado y procesamiento de carne, que forma parte de la misma cadena de producción, es menos importante pero significativa para la economía local en relación con la nacional. La empresa Grupo Porcícola Mexicano destaca como una de las más importantes en la cría de ganado en pie y carne en canal tanto en el estado, como en el país; su producción se destina al mercado nacional, pero una parte importante de sus ingresos proviene de las exportaciones (Grupo Porcícola Mexicano s/f).

Las siguientes ramas tienen una presencia importante, pero menor en comparación con las mencionadas: en el sector primario, la explotación avícola y la acuicultura animal; en el secundario, la generación y trasmisión de energía eléctrica; minería de minerales no metálicos; la molienda de granos y semillas oleaginosas; matanza, empacado y procesamiento de carne; elaboración de productos de panadería y tortillas; confección de otros artículos textiles y de prendas de vestir, y en el terciario sobresalen varios tipos de transporte; consultorios dentales y hospitales; centros nocturnos; servicios de almacenamiento; administración pública; alquiler de automóviles y telefonía celular. Los coeficientes de localización simple de estas ramas son superiores a dos unidades pero menores a seis (véase figura 3).

A manera de conclusión preliminar y con base en la descripción de esta sección, se puede afirmar que la economía yucateca está conformada para satisfacer el mercado local, pues la mayoría de los sectores producen bienes para consumo de los hogares. Hay actividades altamente especializadas cuya producción satisface la demanda local y genera excedentes que se comercializan en otras entidades del país y, en menor importancia, en otros países; la mayoría de ellas está aislada, pues tiene pocos vínculos interindustriales ya que está dedicada a la producción primaria, y su demanda de insumos intermedios externos es alta. 


\section{Análisis estructural de la economía de Yucatán ${ }^{8}$}

Multiplicadores de empleo e ingreso

En la figura 4 se presentan los resultados de la clasificación de los sectores por la capacidad en la creación de empleo, según la normalización de los multiplicadores-columna de empleo. Las actividades clasificadas como altas generadoras de empleo son las que cuentan con multiplicadores sector-economía superiores al promedio de las restantes. Las consideradas como bajas generadoras de empleo son las que tienen multiplicadores sector-economía inferiores al promedio de todas.

\section{Figura 4}

Clasificación de ramas de actividad según su impacto en la generación de empleo

\begin{tabular}{|l|c|c|c|c|c|c|}
\hline Clasificación & $\begin{array}{c}\text { Número } \\
\text { de ramas }\end{array}$ & $\begin{array}{c}\text { Miles de } \\
\text { pesos } \\
\text { PIB }\end{array}$ & Trabajadores & $\begin{array}{c}\text { Miles de } \\
\text { pesos } \\
\text { PIB por } \\
\text { trabajador }\end{array}$ & $\begin{array}{c}\% \\
\text { PIB }\end{array}$ & Trabajadores \\
\hline Mayor al promedio & 66 & 8291853 & 153198 & 148 & 9 & 39 \\
\hline Menor al promedio & 150 & 88155541 & 242836 & 670 & 92 & 61 \\
\hline Total & 216 & 96447394 & 396034 & 818 & 100 & 100 \\
\hline
\end{tabular}

Fuente: elaboración propia, con base en los datos de la MIPE, 2003, de la figura 1.

La economía local tiene poca capacidad para crear empleo formal, ya que sólo se generan en promedio por cada millón de pesos de incremento en la demanda final de un determinado sector; cuatro de forma directa y sólo uno de manera indirecta. Estos valores indican la poca formalidad de la actividad productiva y su baja vinculación con el resto de los sectores locales. Las actividades con

\footnotetext{
${ }^{8}$ Debido a lo extenso del artículo y por razones de espacio, en esta sección se omite la lista de ramas, que comprende hasta 216 actividades, con altos y bajos multiplicadores y por tipo de producción, según encadenamientos directos y totales. Si los lectores así lo desean, pueden solicitar la versión completa a los autores.
} 
gran repercusión directa e indirecta en el empleo por unidad de producto tienen una participación reducida en la economía, ya que representan 9 por ciento del PIBE. En contraste, las de alta participación (91 por ciento) se caracterizan por sus bajos efectos multiplicadores en la generación de empleo formal, tanto por su escasa vinculación productiva como por ser unidades poco intensivas en mano de obra por unidad de producto. Que las actividades sean poco intensivas en mano de obra no significa que lo sean en capital físico y de alto valor agregado por trabajador.

El grupo de ramas con multiplicadores de ingreso menores al promedio representa 93 por ciento del PIBE y 96 del empleo (véase figura 5). Incluye 149 ramas, en su mayoría del sector servicios, comercio, construcción y primario; las que tienen multiplicadores mayores al promedio son las menos numerosas, con 67 ramas de actividad, la mayoría del sector manufacturero. La participación de este grupo en el PIBE y empleo es reducida, de 7 y 4 por ciento, respectivamente. El multiplicador promedio de ingreso tipo i de las ramas de la economía local es limitado, de 1.22, lo que indica que los efectos directos e indirectos en el ingreso de una expansión de cada una de las ramas sobre la economía en su conjunto son muy débiles, debido a la poca integración productiva de las actividades. El multiplicador con un valor de 1.22 indica que el efecto directo en el ingreso, de un aumento de un millón de pesos en la demanda final del sector $\mathrm{j}$, se reproduce 1.22 veces en el conjunto de la economía.

Figura 5

Multiplicador en el ingreso tipo I

\begin{tabular}{|l|c|c|r|r|r|}
\hline Intensidad & Número de ramas & РIB & \multicolumn{1}{c|}{$\%$} & Empleo & $\%$ \\
\hline Mayor al promedio & 67 & 6441 & 7 & 15615 & 4 \\
\hline Menor al promedio & 149 & 90006 & 93 & 380419 & 96 \\
\hline Total & 216 & 96447 & 100 & 396034 & 100 \\
\hline
\end{tabular}

Fuente: elaboración propia, con base en los datos de la MIPE, 2003, de la figura 1. 
Oferta final e intermedia

La producción local se destina a satisfacer la demanda final de bienes y servicios (91 por ciento), principalmente para el mercado local (62). Destaca el consumo de hogares (41), le siguen, en menor importancia, inversión (14) y consumo gobierno (7). Las exportaciones interestatales e internacionales representan más de la tercera parte del total del valor de la demanda final (38 por ciento), y la elaboración de insumos intermedios es poco significativa (9).

Las actividades involucradas en la elaboración de productos de consumo final varían en el grado de vinculación productiva y en sus encadenamientos con el resto de los sectores; se distinguen dos tipos, según su grado de encadenamiento o desarrollo de proveedores locales: las productoras de bienes y servicios para el consumo final, que se dedican al procesamiento de insumos intermedios y que están fuertemente vinculadas a la economía (manufactura final); las que producen bienes de consumo final no manufacturados $y$, por lo tanto, carecen de vinculación productiva por la naturaleza de su producto o por alto consumo de insumos importados (producción primaria final). En la elaboración de bienes para cubrir la demanda final predomina el último grupo de actividades (primarios de producción final); representan 72 por ciento del PIBE y 76 del empleo formal. Por su parte, las actividades de manufactura final, cuyos bienes integran un alto componente local y su producción pasa por procesos de manufactura para su destino al consumo final, ocupan 10 por ciento del PIBE y 6 del empleo formal. En la figura 6 se presentan los resultados obtenidos por tipo de producción.

La oferta de bienes intermedios de origen local es marginal, representa tan sólo 9 por ciento de la producción total (vBP). Las actividades que producen dichos bienes son las que generan menor riqueza, 18 por ciento del PiBE, y 18 de empleo. La mayor parte del grupo de actividades que ofrece bienes intermedios tiene baja demanda de insumos intermedios locales (producción primaria intermedia) debido, en parte, a la naturaleza del producto que elaboran ya que no requieren procesos de manufactura o por su alto consumo de insumos importados de otros estados o países. Este tipo de sectores de producción primaria intermedia, con baja vinculación 
productiva, representan menos de la quinta parte del PIBE (15 por ciento) y del empleo formal (16). Las actividades con procesos de manufactura en la elaboración de bienes intermedios (manufactura intermedia) tienen escasa importancia en términos de participación en el PIBE (3 por ciento) y empleo (2).

La economía yucateca se caracteriza por la presencia de actividades que utilizan una cantidad reducida de insumos locales, y cuya producción se destina a satisfacer la demanda final de bienes y servicios, sobre todo para el consumo de los hogares. Los insumos intermedios demandados por la industria local provienen de otros estados (57.74 por ciento) y en menor medida de otros países (18.82); sólo 23.44 de ellos son locales.

\section{Figura 6}

Tipos de producción y su importancia en la economía local

\begin{tabular}{|c|c|c|c|}
\hline & & \multicolumn{2}{|c|}{ Encadenamiento hacia adelante } \\
\hline & & Alto & Bajo \\
\hline \multirow[t]{2}{*}{$\begin{array}{c}\text { Encadenamiento } \\
\text { hacia atrás }\end{array}$} & Alto & $\begin{array}{l}\text { Manufactura intermedia } \\
\text { Empleados: } 8733(2.21 \%) \\
\text { Número de ramas: } 21 \\
\text { PIB: } \$ 2668257 \\
\text { mp }(2.77 \%)\end{array}$ & $\begin{array}{l}\text { Manufactura final } \\
\text { Empleados: } 24019(6.06 \%) \\
\text { Número de ramas: } 53 \\
\text { PIBE: } \$ 9701545 \mathrm{mp} \\
(10.06 \%)\end{array}$ \\
\hline & Bajo & $\begin{array}{l}\text { Primaria intermedia } \\
\text { Empleados } 63861 \text { (16.13\%) } \\
\text { Número de ramas: } 51 \\
\text { PIBE } \$ 14526174 \\
\text { mp }(15.06 \%)\end{array}$ & $\begin{array}{l}\text { Primario final } \\
\text { Empleados } 299411 \\
(75.60 \%) \\
\text { Número de ramas: } 91 \\
\text { PIBE \$69 } 551418(72.11 \%)\end{array}$ \\
\hline
\end{tabular}

$\mathrm{mp}=$ millones de pesos

Fuente: elaboración propia, con base en los datos de la MIPE, 2003, de la figura 1; INEGI (2004 y 2005b); SIAP-SAGARPA (2010).

Importaciones interestatales e internacionales

En 2003, las importaciones interestatales e internacionales ascendieron a 69965 millones de pesos, de los cuales 48784 millones (69.73 por ciento) correspondieron a la importación de insumos 
intermedios llevada a cabo por las unidades productivas locales y 21181 millones (30.27) al valor de las importaciones de bienes para la demanda final (el consumo de hogares y la formación bruta de capital de las empresas locales). El grueso de las importaciones de insumos intermedios, 75 por ciento, proviene de otros estados del país y 25 del extranjero; se puede suponer el mismo comportamiento en las importaciones de demanda final, es decir, la mayor parte proviene de otras entidades.

Las importaciones se realizan para satisfacer los requerimientos de insumos de las unidades productivas locales que elaboran bienes y prestan servicios destinados al consumo final de los hogares de Yucatán; los productos yucatecos tienen componentes foráneos. Las importaciones internacionales de insumos intermedios reportada por la SEFOE para 2004 ascendió a 1014.02 millones de dólares, a un tipo de cambio de 11.27 pesos por dólar da un valor de 11428 millones de pesos, muy cercano al estimado por esta investigación para 2003, de 11990 millones. $^{9}$

Las actividades de manufactura final utilizan en promedio más insumos intermedios locales (véase figura 7); las de producción primaria final e intermedia consumen en su mayoría insumos intermedios de otras entidades federativas. Representan el grupo de actividades con mayor presencia en la economía local tanto en términos de empleo formal (92 por ciento), como por su participación en el PiBE (87). Las de manufactura intermedia emplean de forma equilibrada insumos locales y de otros estados del país. El consumo de insumos intermedios internacionales es similar en cada tipo de producción, representa alrededor de 21 por ciento (promedio) del total utilizado durante el proceso de producción de cada grupo.

\footnotetext{
${ }^{9}$ Las estadísticas de la SEFOE y las obtenidas por esta investigación son aproximadamente iguales en el valor reportado de las importaciones de insumos intermedios internacionales totales, pero no coinciden en el valor por rama de actividad. Esto es así, ya que el presente trabajo toma la metodología de clasificación del scian 2002 y la MIP, donde las importaciones son clasificadas según la rama productiva de la empresa que las emplea, como insumos intermedios para llevar a cabo su proceso productivo. En cambio, la SEFOE clasifica los datos de las importaciones por fracción arancelaria con base en la naturaleza del producto que se importa. Dado que la SEFOE toma como universo de estudio a las empresas locales, se deduce que el valor de las importaciones que reporta se refieren a los insumos intermedios.
} 


\section{Figura 7}

Consumo de insumos según origen por tipo de producción, millones de pesos

\begin{tabular}{|l|r|c|c|c|c|c|c|}
\hline Tipo & $\begin{array}{c}\text { Insumos } \\
\text { totales }\end{array}$ & Estatales & $\%$ & $\begin{array}{c}\text { Otros } \\
\text { estados }\end{array}$ & $\%$ & Internacionales & $\%$ \\
\hline Manufactura final & 14205.82 & 6264.30 & 48.89 & 5591.22 & 29.11 & 2350.30 & 21.99 \\
\hline $\begin{array}{l}\text { Manufactura } \\
\text { intermedia }\end{array}$ & 4283.32 & 1144.65 & 40.73 & 2339.29 & 38.50 & 799.38 & 20.77 \\
\hline Primario final & 35361.81 & 5881.97 & 19.06 & 22610.89 & 58.17 & 6868.94 & 21.67 \\
\hline $\begin{array}{l}\text { Primario } \\
\text { intermedia }\end{array}$ & 9870.19 & 1646.55 & 18.73 & 6252.62 & 61.50 & 1971.02 & 19.77 \\
\hline Total & 63721.14 & 14937.47 & & 36794.03 & & 11989.64 & \\
\hline
\end{tabular}

Fuente: elaboración propia, con base en los datos de la MIPE, 2003, de la figura 1.

Encadenamientos totales hacia atrás y hacia adelante

En la figura 8 se presentan los resultados agregados.

- Sectores base $b_{j}{ }^{n}<1$ y $v_{i}^{n}>1$. Son los más beneficiados cuando la economía crece. Sus productos tienen gran demanda por otras actividades productivas, pero están poco vinculados hacia atrás. Son los de menor presencia en la economía local, en términos de su participación en el PIBE (8 por ciento) y empleo (5).

- Sectores clave $b_{j}^{n}>1$ y $v_{i}^{n}>1$. Son los que podrían causar cuellos de botella, son de paso obligado de los flujos interindustriales en la economía local, donde tienen poca presencia tanto en términos de su participación en el PIBE (10 por ciento) como en el empleo (13).

- Sectores de fuerte arrastre $b_{j}^{n}>1$ y $v_{i}^{n}<1$. Son los que estimulan el crecimiento económico, dado sus altos encadenamientos totales (no sólo directos) hacia atrás. Representan alrededor de una quinta parte de la economía local, tanto en términos del PIBE (21 por ciento) como del empleo (22).

- Sectores independientes $b_{j}^{n}<1 y v_{i}^{n}<1$. Son los que están aislados del resto del sistema productivo, responden a impulsos externos 
de la economía; no estimulan el crecimiento económico ni responden a la dinámica de la actividad productiva. Representan la mayor proporción del PIBE (61 por ciento) y el mayor empleador local (59).

\section{Figura 8}

Clasificación sectorial según valores de índices de encadenamientos totales

\begin{tabular}{|l|r|r|r|r|r|r|}
\hline Tipo & $\begin{array}{c}\text { Número } \\
\text { de } \\
\text { sectores }\end{array}$ & $\begin{array}{c}\text { Millones } \\
\text { PIB }\end{array}$ & Trabajadores & $\begin{array}{c}\text { Miles de } \\
\text { pesos } \\
\text { PIB por } \\
\text { trabajador }\end{array}$ & $\%$ PIB & $\begin{array}{c}\% \\
\text { Trabajadores }\end{array}$ \\
\hline Base & 39 & 8034 & 21209 & 378.78 & 8.33 & 5.36 \\
\hline Clave & 34 & 9748 & 52135 & 186.97 & 10.11 & 13.16 \\
\hline Fuerte arrastre & 42 & 19945 & 88350 & 225.75 & 20.68 & 22.31 \\
\hline Independientes & 101 & 58721 & 234340 & 250.58 & 60.88 & 59.17 \\
\hline Total & 216 & 96447 & 396034 & 243.53 & 100.00 & 100.00 \\
\hline
\end{tabular}

Fuente: elaboración propia, con base en los datos de la MIPE, 2003, de la figura 1.

\section{Recomendaciones de política pública}

A partir del cruce de las variables consideradas en la investigación, es posible identificar combinaciones de sectores y ramas de actividad económica, como base para diseñar estrategias de fomento económico con objetivos diferenciados, y son las siguientes:

1. Actividades estratégicas: las ramas que estimulan el crecimiento económico, gracias a sus altos encadenamientos totales hacia atrás, identificados en el estudio como sectores de fuerte arrastre. También se consideran las actividades de paso obligado de los flujos interindustriales en la economía local, llamados sectores clave.

2. Actividades altamente generadoras de empleo: las que tienen multiplicador del empleo superior a la media de la economía 
estatal. Se definen por el número de empleos creados por cada millón de pesos de aumento en la demanda final.

3. Actividades altamente generadoras de ingreso: las que tienen multiplicador del ingreso superior a la media de la economía estatal. Se definen por el número de veces en que el aumento en el ingreso inicial se reproduce en el sistema económico, por millón de pesos de incremento en la demanda final.

4. Actividades con alta presencia en la economía local: las de elevado coeficiente de localización simple. Éste indica que la participación de la rama en la economía local es igual a tantas veces (valor del coeficiente) la del promedio nacional.

5. Actividades altamente generadoras de empleo y baja productividad: son las estratégicas o bien con elevados efectos multiplicadores de empleo, pero con bajos índices de productividad media, definida como el cociente entre los porcentajes de participación de cada rama en el piBE y en el empleo formal. Los sectores con baja productividad representan 82 por ciento del empleo formal total. La elevación de la productividad media de tales sectores se traduciría en mejoras sensibles en el ingreso, en la actividad económica y el empleo mismo.

Para enfrentar los mayores rezagos de la economía local, en un contexto de limitación de los fondos públicos de fomento, se requiere de estrategias de promoción económica diferenciadas ${ }^{10}$ en función de los objetivos por alcanzar; entre otras, es posible pensar en las siguientes: ${ }^{11}$

Promoción del empleo formal. Es la orientada a fomentar las ramas de actividad definidas como estratégicas (con fuerte arrastre y clave), que a la vez tienen un elevado multiplicador de empleo: acuicultura animal; pesca; confección de prendas de vestir; agricultura; preparación de hilados y fibras textiles y fabricación de hilos; confección de otros productos

\footnotetext{
${ }^{10}$ Las estrategias que aquí se sugieren tienen una aplicación de corto a mediano plazo, en un horizonte de planeación para cinco años, pues se basan en la estructura de la economía en 2003 y en el supuesto de estabilidad temporal de coeficientes técnicos a corto plazo.

${ }^{11}$ Las actividades que aparecen en cursivas se incluyen en más de una estrategia.
} 
textiles, excepto prendas de vestir; elaboración de jabones, limpiadores y preparaciones de tocador; impresión e industrias conexas; productos de plástico; fabricación de artículos metálicos, forjados y troquelados; de estructuras metálicas y productos de herrería; de alambre, productos de alambre y resortes; maquinado de piezas metálicas y fabricación de tornillos.

Promoción del empleo remunerador. Es la orientada a mejorar los sueldos y salarios en la economía del estado, mediante la promoción de las ramas de actividad que tienen a la vez elevados multiplicadores de ingreso y empleo: productos relacionados con los muebles; explotación de ovinos y caprinos; jabones, limpiadores y preparaciones de tocador; maquinaria y equipo para las faenas agropecuarias; otra maquinaria y equipo para la industria; maquinaria y equipo para la industria metalmecánica; muebles de oficina y estantería; impresión e industrias conexas; maquinado de piezas metálicas y fabricación de tornillos.

Promoción del ingreso y la actividad económica. Es la orientada a las actividades estratégicas con elevado multiplicador de ingreso: servicios relacionados con la minería; elaboración de productos lácteos; matanza, procesamiento y empacado de carne de ganado y aves; fabricación de telas; de celulosa, papel y cartón; de azúcar, chocolates, dulces y similares; curtido y acabado de cuero y piel; aserrado y conservación de la madera; confección de alfombras, blancos y similares; moldeo por fundición de piezas metálicas; fabricación de hules, resinas, fibras químicas; de productos farmacéuticos; de productos a base de arcillas y minerales refractarios; de vidrio y productos de vidrio; de herramientas de mano sin motor y utensilios de cocina metálicos; de calderas, tanques y envases metálicos; generación y trasmisión de energía eléctrica; producción de fertilizantes, pesticidas y otros agroquímicos; de pinturas, recubrimientos, adhesivos y selladores; de jabones, limpiadores y preparaciones de tocador; de productos de papel y cartón; impresión e industrias conexas; elaboración de derivados del petróleo y el carbón; de productos químicos básicos; de otros productos químicos; de productos de hule; maquinado de piezas metálicas y fabricación de tornillos y de otros artículos metálicos.

Promoción de procesos de clusterización. Es la orientada a promover las actividades definidas como estratégicas que ya tienen fuerte presencia en la economía local, y que además está probado que son 
generadoras de empleo: explotación de porcinos; acuicultura animal; pesca; edificación no residencial; construcción de vías de comunicación; otras construcciones de ingeniería civil u obra pesada; matanza, empacado y procesamiento de carne de ganado y aves; preparación y envasado de pescados y mariscos; elaboración de productos de panadería y tortillas; confección de prendas de vestir; acabado y recubrimiento de textiles; explotación de otros animales (apicultura); minería de minerales no metálicos; molienda de granos y semillas oleaginosas; generación y trasmisión de energía eléctrica; confección de otros productos textiles, excepto prendas de vestir; fabricación de cemento y productos de concreto; de cal, yeso y productos de yeso.

Promoción de la productividad en sectores altamente empleadores. Es la orientada a promover la elevación de la productividad en los sectores y ramas altamente empleadoras, como las agropecuarias y la manufactura en general: agricultura; ganadería; explotación forestal; pesca e industria manufacturera.

\section{Conclusiones}

La presente investigación ha puesto de relieve algunos de los mayores rezagos de la economía yucateca, entre los que destacan: baja productividad en los principales sectores y ramas económicos; población ocupada con sueldos y salarios entre los más reducidos a escala nacional; bajo nivel de formalidad de la actividad productiva; poca capacidad de generación de empleo formal; enclaves de producción manufacturera con muy poco o nulo aporte tecnológico a la planta industrial; manufactura ligera con tecnología tradicional y baja productividad; actividades terciarias con poca generación de riqueza; actividades económicas con escasa o nula vinculación con los sectores locales, por lo que su incidencia en el crecimiento y generación de riqueza es reducida; los sectores con preponderancia en la economía local se caracterizan por su aislamiento del sistema productivo, sin vínculos directos e indirectos con las industrias. Los encadenamientos totales son débiles o inexistentes; los vínculos con proveedores locales son escasos y el abasto de materias primas a industrias regionales también son exiguos. 
En este trabajo se realiza una primera aproximación a la caracterización de la estructura de interrelaciones entre los sectores productivos que conforman la economía de Yucatán. El diagnóstico parte de la estimación por métodos matemáticos y con base en información secundaria de fuentes oficiales de una MIPE, como una primera aproximación y un primer intento por reorganizar la información disponible sobre la actividad productiva en un sistema contable de doble entrada. En la elaboración de la MIPE se adoptaron diversos supuestos sobre el comportamiento de la actividad productiva local, en relación con la nacional y la estructura de la demanda final. Por lo anterior, los resultados obtenidos deben ser tomados como una primera caracterización de la economía local y deberán ser complementados y corroborados en diferentes estudios sectoriales de corte empírico.

Como primera aproximación a la problemática del sector productivo, este trabajo da la pauta para el desarrollo de investigaciones futuras orientadas a abordar los factores que deberán atenderse para el fortalecimiento de las cadenas productivas locales, el desarrollo de proveedores, el abasto de insumos intermedios y la vinculación productiva interindustrial.

Recibido en noviembre de 2010 Aceptado en mayo de 2011

\section{Bibliografía}

Albornoz, Lilian. 2000. El análisis crucial de las maquiladoras en Yucatán: el impacto de la trasferencia de tecnología. Revista de Economía I (54): 71-86.

Armenta, Aída Beatriz. 2007. Modelo insumo-producto. Villahermosa: Universidad Juárez Autónoma de Tabasco.

Bonfiglio, Andrea y Francesco Chelli. 2008. Assessing the Behavior of Non-survey Methods for Constructing Regional Input-output 
Tables Through a Monte Carlo Simulation. Economic Systems Research 20 (3):243-258.

Canto, Rodolfo. 2001. Del henequén a las maquiladoras. La política industrial en Yucatán 1984-2001. México: Instituto Nacional de Aadministración Pública, UADY.

Chapa, Joana, Edgardo A. Ayala y Diana Hernández. 2009. Modelo de insumo producto para el noreste de México. Ciencia UANL XII (4): 409-416.

Chenery, Hollis y Tsunehiko Watanabe. 1958. An International Comparation of the Structure of Production. Econometrica 26 (4): 487-521.

Dávila, Alejandro. 2002. Matriz insumo-producto de la economía de Coahuila e identificación de sus flujos intersectoriales más importantes. Economía Mexicana, nueva época XI (1): 79-162.

Eurostat. 2002. The ESA 95 Input Output Manual. Compilation and Analysis. Version: August 2002.

Flegg, Anthony T., y Timo Tohmo. 2011. Regional Input-output Tables and the FLQ Formula: A Case Study of Finland. Regional Studies DOI: $10.1080 / 00343404.2011 .592138$ : 1-19.

y C. D. Webber. 2000. Regional Size, Regional Specialization and the FLQ Formula. Regional Studies 34 (6): 563-569.

1997. On the Appropriate Use of Location Quotients in Generating Regional Input-output Tables: Reply. Regional Studies 31 (8): 795-805.

y M.V. Elliot. 1995. On the Appropriate Use of Location Quotients in Generating Regional Input-output Tables and the FLQ Formula. Regional Studies 29 (6): 547-561. 
Fuentes, Noé A. 2009. Encadenamientos intersectoriales de la industria maquiladora de exportación en Baja California. región y sociedad 21 (44): 171-194.

, Sonia Y. Lugo Morones y Mario A. Herrera Sánchez. 2004.

Matriz de insumo-producto para Baja California: un enfoque híbrido. México: Miguel Ángel Porrúa.

Gilchrist, Donald y Larry St. Louis. 2004. An Algorithm for the Consistent Inclusion of Partial Information in the Revision of Input Output Tables. Economic Systems Research 16 (2):149-156.

Grupo Porcícola Mexicano. s/f. http://www.keken.com.mx/ (julio de 2010).

Han, Xiaoli. 1995. Structural Change and Labor Requirement of the Japanese Economy. Economic Systems Research 7 (1): 47-66.

Hirschman, Albert. 1973. La estrategia del desarrollo económico. México: Fondo de Cultura Económica.

INEGI. 2010. Encuesta nacional de ocupación y empleo. Consulta interactiva de datos. http://www.inegi.org.mx/est/contenidos/ Proyectos/encuestas/hogares/regulares/enoe/Default.aspx

. 2007. Cómo se hace la ENOE. Métodos y procedimientos. Aguascalientes: INEGI.

. 2007. Censo agrícola ganadero y forestal. http://www. inegi.org.mx/est/contenidos/proyectos/Agro/ca2007/Resultados_Agricola/default.aspx (abril de 2010).

.2005a. Censo económico 2004. Sistema Automatizado de Información Censal saIC 5.0. Disco compacto.

2005b. Anuario estadístico del estado de Yucatán. Gobierno del Estado de Yucatán e INEGI. http://www.inegi.gob.mx/est/ contenidos/espanol/sistemas/aee05/estatal/yuc/index.htm 
2004. Metodología de los censos económicos. http:// www.inegi.gob.mx/est/contenidos/espanol/metodologias/ censos/metodo_ce2004.pdf (marzo de 2010).

2003-2007. Sistema de Cuentas Nacionales de México, Producto Interno Bruto por Entidad Federativa, base 2003. http://inegi.mx/prod_serv/contenidos/espanol/bvinegi/productos/derivada/regionales/pib/PIBE2007.pdf

2002. Sistema de Clasificación Industrial de América del Norte. MéxiCO: INEGI.

2000. Censo general de población y vivienda. http:// www.inegi.org.mx (marzo de 2010).

. s/f. Producto interno bruto por entidad federativa. http:// dgcnesyp.inegi.org.mx/bdiesi/bdie.html (abril de 2010).

Junius, Theo y Jan Oosterhaven. 2003. The Solution of Updating or Regionalizing a Matrix with Both Positive and Negative Entries. Economic Systems Research 15 (1): 87-96.

Leontief, Wassily. 1986. Input-output Economics. Nueva York: Oxford University Press.

Mariña, Abelardo. 1993. Insumo-producto: aplicaciones prácticas al análisis económico estructural. México: Universidad Autónoma MetropolitanaAzcapotzalco.

Miller, Ronald E., y Peter D. Blair. 2009. Input-output Analysis, Foundations and Extensions. Londres: Cambridge University Press.

Naciones Unidas. 1999. Handbook of Input Output Tables Compilation and Analysis. Nueva York.

Núñez, Gaspar y Ángel S. Cruz. 2009. Matriz de insumo producto de Oaxaca y un análisis de su economía. Revista Mexicana de Economía Agrícola y de los Recursos Naturales 2(3): 104-125. 
OCDE. 2008. Estudios territoriales de la OCDE Yucatán, México. México: Fundación Plan Estratégico de Mérida.

Rasmussen, P. N. 1956. Studies in Intersectoral Relations. Amsterdam: North Holland Publishing Company.

SEFOE. s/f. Datos preliminares de la Dirección de Análisis y Evaluación de Proyectos de la Secretaría de Fomento Económico, Gobierno del Estado de Yucatán. http://www.sefoe.yucatan.gob. $\mathrm{mx} /$ docpublicaciones/200604053888.pdf

SIAP-SAGARPA. 2010. Sistema de Información Agroalimentaria y Pesquera. http://www.siap.gob.mx/ (mayo de 2010).

Ten Raa, Thijs. 2005. The Economics of Input-output Analysis. Londres: Cambridge University Press.

Tohmo, Timo. 2004. New Developments in the Use of Location Quotients to Estimate Regional Input-output Coefficients and Multipliers. Regional Studies 38 (1): 43-54. 